the stratosphere. In the second paper Shaw carries the application of the equations somewhat further and making certain assumptions works out temperature and pressure from wind velocity at successive heights. There is also a statement of certain axioms or laws of motion and applications of the laws in practical meteorology. The laws stated briefly are (1) relation of motion to pressure; (2) computation of pressure and application of gaseous laws; (3) convection, which is expressed as the descent of colder air in contiguity with air relatively warmer; (4) the limit of convection, defined as that portion of the atmosphere where there exists a sensible fall of temperature with height, and (5) the law of saturation.

The irregular variations in temperaturedifference as given by a pair of soundings with registering balloons; and the curious local irregularities of wind disclosed by pilot balloon ascents, hitherto explained as uncertainties of observation, are now in Dr. Shaw's opinion seen to be important as indicating complex structure of the atmosphere. If Shaw's reasoning is correct then it may be possible to get from one pilot balloon as much information for practical purposes as from three registering balloons. The distribution of isobars at 4 kilometers as computed by Teisserenc deBort is also considered and the law of convection applied. One sentence is significant and may be quoted. "All the main air-currents of the globe have pressure-distributions to guide them. They can not usefully be called convection currents." There is also a most suggestive reference to the flow of air down the Arctic and Antarctic slopes. It appears likely that whenever in a mass of air, temperature-fall is in the opposite direction to pressure-fall, great change in the horizontal distribution of pressure underneath is the result; and many of our local variations of pressure may fairly be attributed to the reactions which these cold masses of air offer to the attempt (in the end futile) of the upper air to steer them round the pole from west to east. If left to themselves they would circulate in opposition to the circulation of the upper air with which they are in perpetual conflict.
With regard to tropical revolving storms, Dr. Shaw holds that these must be considered under a different head, namely that of turbulent motion, and intimates that papers are forthcoming on this subject.

The third paper is largely made up of tables for facilitating computation in problems like those referred to above.

In the fourth paper our author deals with examples taken from typical cases of atmospheric structure selected by Mr. Cave for illustration by means of photographs of models in the "Structure of the Atmosphere in Clear Weather." Five distinct classes are considered. $\mathrm{He}$ introduces a new conception, that of operative pressure. How this is produced does not appear but if its existence be granted and the thermal structure of the underlying air, then the deductions drawn follow with mathematical precision. Instances of irregular distribution of temperature are explained and in the case of one marked inversion it is imagined that the construction was formed above a pool of cold air such as would be found over fog. The result of recent work is to show that as regards the weather of the present and the immediate future, the operative pressure distribution and the thermal structure of the atmosphere between it and the ground ought to be regarded as independent variables.

Shaw looks forward to the issue of maps of the upper levels wherein cloud observations and pilot balloon data will show what the actual circulation at a given level is. From these we may estimate the effect on pressure distribution in lower levels.

The papers taken together give a working plan so far as general atmospheric motion is concerned and form a distinct contribution to the solution of the problem of the life-history of cyclones and anti-cyclones.

Alexander MoAdie

Blue Hill Meteorological Observatory

\section{NAVIGATION WITHOUT LOGARITHMS}

Captain Guyou, of the French navy, a mathematician of note, author of valuable 1 "Nouvelles Tables De Navigation," Emile Guyou. Berger-Levrault, Editeurs, Paris. 
works dealing with the problems of navigation and member of various learned societies, has devoted part of his time since his retirement to producing tables from which a "line of position" (Sumner line) can be worked and the ship's position thereon approximately determined with the least labor and in shortest time.

The tables are preceded by a condensed explanation for the benefit of those who wish to understand their mathematical development; but the many practical and efficient navigators who bother little with theory will be interested to know what Captain Guyou does, without having to concern themselves as to how he does it.

Gird up your imagination and conceive the world and the heavenly bodies as standing still; suppose, further, that your ship is connected with a heavenly body not directly overhead-the sun, for instance-by a steel rod having a universal bearing where attached to the ship and another where attached to the sun. Start up your engine and let the wheel alone! The ship will be so controlled by the rod that she must describe an enormous circle on the face of the waters, having for its center that point on the earth's surface at which the sun is then in the zenith. Meanwhile, the rod describes an enormous cone with the sun at the apex, and when we consider that the sun's altitude, or height, is measured by the angle enclosed between the rod and the base of the cone (roughly), we can realize that an observer on board, taking the sun's height with a sextant at frequent intervals, will get the same height all the way around the circle.

The foregoing must be qualified in practise because the world does not stand still and the ship is not going to sail on a circular course; true, she is on the circumference at the moment of observation, but she may be crossing it at any angle because the position of the center of the circle and the direction in which the circumference trends depend upon the sun and not upon the ship.

If the ship be at rest, the observed altitude of the sun will change continually from hour to hour because of the apparent motion of the sun in his diurnal course. If the ship be in motion, the observed altitude of the sun will likewise change from hour to hour not only because of the sun's apparent diurnal motion, but also, although by a comparatively small amount, because of the fact that the ship is under way pursuing a certain course and making a certain rate of speed. It is evident that she may be considered to be crossing a circumference at any moment and that all sun observations taken at that moment from ships on different parts of that circumference will show the same altitude.

Two problems present themselves!

First: To find the circumference.

Second: To find the point at which the ship was crossing it when the observation was taken.

They have been dealt with in various ways. An able French admiral, Marcq de SaintHilaire, evolved an admirable solution by working out the distance from the deadreckoning point-almost always more or less erroneous-to the circumference; his method may be outlined as follows: the navigator measures the height with a sextant, notes the time, then calculates the height he would have gotten at the dead-reckoning point at the moment of observation. If the two heights agree the dead reckoning may be accepted as correct, for it coincides with the circumference; this occurs but rarely; as a usual thing the dead-reckoning point falls several minutes (of distance) outside the circle or within it, two heights result, and the difference between them enables the navigator to work out the error in distance from dead reckoning to circumference. This solves the first problem!

The solution of the second is simpler because the dead reckoning is sufficiently reliable to limit to a few sea-miles that portion of the circumference at some point in which the observation must have been taken. Since the circle is very large this small portion of circumference may be accepted as a straight line. It is the navigator's "Line of Position" and the ship's crossing point thereon is closely approximated by the direction of the center 
of the circle from the dead-reckoning point, which direction-since the sun is the zenith of the circle's center-is rendered by the azimuth.

But this method, though far the most desirable theoretically, involves the danger of error, the time, labor and irritation inseparable from an appalling array of logarithmsI rejoice that I am not called upon to express the sentiments with which a tired and hungry man in oil-skins regards logarithms-the calculation of height at the dead reckoning point calls for a half dozen, the azimuth for three or four more, and these operations are followed by an excursion into trigonometry to localize the result; which result, if you are an amateur, will doubtless be wrong, while, if a professional, you will not have tried it.

With Captain Guyou's tables one enters with true height and declination in a page devoted to the approximate latitude and takes out two numbers, turns to a page devoted to the approximate hour-angle and takes out two more. With these numbers he does one small sum in addition and and two in subtraction, then rules off the ship's position on the chart.

One can only admire the lofty unconcern with which Captain Guyou juggles distances, especially as he juggles them accurately. One of his circles can enclose the greater part of a hemisphere but he does not hesitate to slide it down until the dead-reckoning latitude coincides with the equator where he performs his mathematical feat with the two heights before coolly sliding the circle back again. Of course the objection at once arises that the navigator would not have gotten the same observed and calculated heights on the equator that he did get in higher latitudes, but here Captain Guyou's versatile resource comes into play, for the navigator would have gotten the same number of minutes of difference between the two heights (expressed in minutes of the respective latitudes). This difference, as we have seen above, yields the error in distance between dead reckoning and circumference and from it, in connection with the azimuth, the position can be worked out.

But Captain Guyou does not slide down to the equator merely in search of the abovementioned error. He has another purpose and it is indeed ingeniously accomplished: we all know that the basis of navigation is the spherical triangle and that three parts of ittwo sides and one angle, for instance-must be known before it can be solved. But tables calling for the combination of three known quantities throughout the extent of $90^{\circ}$ of latitude and $360^{\circ}$ of longitude would be ponderous and impractical. With only two known quantities these objections do not obtain, but two known quantities do not suffice to solve the problem. In drawing up his tables Captain Guyou has used three, of which the latitude is the third, and has employed a trig onometrical formula in which the required result is obtained by multiplying functions of the two other known quantities by the tangent of one half the complement of the third (the latitude). Since he has slid his circle down until the (dead reckoning) latitude coincides with the equator his latitude is $0^{\circ}$; the complement $90^{\circ}$; and the tangent $\frac{1}{2} 90^{\circ}=1$, which, as a multiplier, may be disregarded, thus reducing the known quantities which must be considered to two and rendering the tables practicable.

Little knowledge of navigation is required in using them. One must understand reducing observed height to true and correcting the declination for the moment of observation. It is of course necessary to be familiar with the varieties of time used at sea. In figuring, one must know, and observe, the difference between + and -.

These moderate requirements can be mastered in a few evenings and practise may then be begun over an artificial horizon, or otherwise, for the tables include a page of directions which cover all cases and can be blindly followed to a correct result. A general conception of the principles of navigation and the problems involved will come with practise and the necessity of thinking out one's mistakes, and, in a short time, a new hand should be able to work at sight with confidence and accuracy.

WaLter D. Robinson 